\title{
The effects of person-organization, person-group, person-job and person-supervisor fit on retention tendency
}

\author{
Huo-Tsan Chang ${ }^{1}$, Shang-Chih Liao ${ }^{2 *}$, Min-Chih Miao ${ }^{3}$, Xiu-Hui Huang ${ }^{4}$, Hung-Ming Hsu ${ }^{5}$ \\ 1, 2, 3, 4, 5 Graduate Institute of Human Resource Management, National Changhua University of Education, \\ Bao-Shan, Taiwan
}

\author{
Keywords \\ Person-organization fit \\ Person-group fit \\ Person-job fit \\ Person-supervisor fit \\ Retention tendency \\ Received: 14 February 2019 \\ Accepted: 21 March 2019 \\ Published: 24 April 2019
}

\begin{abstract}
Based on the fit and person-in-situation theory, this study investigated the effect of each variable on retention tendency to propose a more comprehensive fit research framework. Taking the semiconductor manufacturing industry in Taiwan as the research population, this study surveyed R\&D personnel in 15 manufacturers. A total of 300 questionnaires were sent out, with the matched samples were valid for a response rate of $72 \%$. To all R\&D personnel, the findings of this study indicate that: i. Person-organization fit is positively related to retention tendency. ii. Person-group fit is positively related to retention tendency. iii. Person-job fit is positively related to retention tendency. iv. Person-supervisor fit is positively related to retention tendency. v. Under the R\&D personnel's multidimensional fits, the person-organization, person-job, and person-supervisor fits have significantly positive effects on the retention tendency, but person-group fit has no significant effect. This study proposed some practical management implications based on the findings.
\end{abstract}

(C) 2019 The Author(s). Published by TAF Publishing.

\section{INTRODUCTION}

With the globalization trend in economic development, enterprises face the competition from both domestic and the global business. Enterprises aim at developing a long-term and sustainable operation, not only the traditional manufacturing methods for OEM shall not be followed, but also more attention shall be centered on innovation of $R \& D$ in order to respond to unpredictable business environment. Nowadays, the consumption pattern is based on novelty and speed, which shortens product life cycle continuously. Therefore, enterprises should also focus on innovation of $R \& D$ so as to become the advantage in differential strategy from their competitors and to enlarge margin of profit for enterprises. R\&D personnel are the key to mastering the competitiveness in enterprise innovation of R\&D. Through consistently innovation and development of new technologies, R\&D personnel enable the company to continuously maintain a leading position and create high operational per- formance. Therefore, companies should take R\&D personnel as the most important asset. Among various industries, high-tech industries with short product life cycles, highly complex work patterns, highly competitive markets, rapid technological changes, and a focus on research and innovation (King, 2016; Li \& Chen, 1999). With those characteristics, high-tech industries should treat $R \& D$ personnel as a critical and core talent of the company in order to maintain competitiveness. High-tech industry in Taiwan has grown rapidly in recent years, which has been considered as one of the most important development directions in terms of national industry policy (Oudat, Ahmad, \& Yazis, 2016; Tsai, 1999). Furthermore the 2017 statistics of the "Science and Technology Statistics" of the National Science Council of the Executive Yuan also indicated that the research and development funds as well as the number of dedicated employees in high-tech companies have been rising year after year. Accordingly, in order to make this research a step closer to the

* corresponding author: Shang-Chih Liao

†email: jliaoamp1688@gmail.com 
industrial development trend, this research take R\&D personnel of high-tech industries as the main research object. Based on the above arguments, it can be seen that R\&D personnel are important and critical human capital in the hightech industry. Hong and Lin (1991) pointed out that in the high-tech industry, a high employee turnover rate not only causes the loss on recruitment and training costs but also the professional skills and practical experience of R\&D personnel are not easy to be accumulated and passed on. In the previous study pointed out that a company suffered the loss would mount 1.2 to 2 times of the demission annual salary, including the recruiting costs, and the gap cost of generating the same amount of productivity between the former staff departure and the new replacement (Nuansoi, Suntiniyompukdee, \& Tahlah, 2017; Phillips, 1990). Fitz-enz (1997) and Rivenbark (2004) have concluded that the turnover of personnel often causes tangible and intangible losses to employers. Accordingly, in addition to paying their salaries, there are still expenses for recruiting, training, employment benefits, insurance, and other relevant costs. Therefore, frequent turnover will bring the employer more losses on opportunity costs. Generally, R\&D personnel recruited by high-tech companies are highly educated and most of them need to be trained and cultivated well to fit into the job after joining the organization. Novices are more likely need to spend 23 years on training, cultivation and practice so as to require $R \& D$ professional skills. Consequently, how to reduce R\&D staff turnover rate on high-tech industries is the primary issue when formulating human resources strategies.

In the previous research of retention and turnover, most scholars use the intend to leave as the research topic. Resignation tendency was the other side of retention tendency, and those two has a significant correlation (Black \& Stevens, 1989). Moreover, Kraut (1975) proposed that retention tendency to be more effective than the resignation tendency in predicting the demonstrated staff turnover inside the organization. Retention tendency is a tendency for a person to be willing to retain in the organization and to do the best for the given responsibility (Kraut, 1975). Therefore, in the current study, we try to dig out the factors contribute to retention tendency. We propose that an individual satisfied his/her job and the environment of organization of his stay. One will have tendency to keep the status what he/she is. For this reason, that person fits the organization, group, job and supervisor is critical to his/her retention tendency. The origin of the concept of fit can be traced back to the concept of $\mathrm{B}=\mathrm{f}(\mathrm{P}, \mathrm{E})$ proposed by Kurt Lewin (Campion, Medsker, \& Higgs, 1993), where B is the behavior of the individual,
$\mathrm{P}$ is the person of the individual, and $\mathrm{E}$ is the environment around the individual.

In discussing the relationship of fit, it can be divided into the supplementary fit and complementary fit (Muchinsky \& Monahan, 1987). Supplementary fit means that the characteristics of the individual and the environment are mutual matching or similarity existing, whereas complementary fit refers to that individual attributes can complement the insufficiency of environmental attributes. According to the concept of supply and demand (Edwards, 1991), proposed the individual and job fit model as a different angle for argument. When professional characteristics and job characteristics provided by the job can achieve personal desires, needs, and preferences, it is called a desire-supplies fit. When the employee's ability meets the requirements of the job, it is called the demand-abilities fit. Accordingly, the person-organization fit model combines the above two fit viewpoints (Kristof, 1996; Rehman, 2017). When the person and the organization are to be consistent or fit, at least the resources provided by one party is required by the other party, or both parties have similar basic attributes, or both of the above two are existing. This current study will use the supplementary and complementary fit viewpoints to support our argument (Muchinsky \& Monahan, 1987; Rijal, 2016).

The concept of fit has been thriving in the research and application of human resource management, psychology, and organizational behavior for years. In organizational behavior, scholars divide the fit of individuals and situations into two categories: the fit of person and job, and the fit of person and organizations. In the some previous research only involved one or two fit types, and focused on person and organization fit or person and job fit (Edwards, 1991; Kristof, 1996; Pimonratanakan \& Pooripakdee, 2017) others verified that person and job fit, person and organization fit, and employee performance (Kolenko \& Aldag, 1989), organizational identity (Saks \& Ashforth, 1997), organizational commitment (Vancouver \& Schmitt, 1991), job satisfaction (Taris \& Feij, 2001), and the resignation willingness (Cable \& Judge, 1996) were significantly related. However, with the Person-in-Situation Theory, the environment one faced may include organization, group, and person. Therefore, the fit between person and organization cannot fully explain employee behavior. Furthermore, Kristof (1996) proposed person environment fit sweeping up person and job fit, person and organization fit, person and attitude fit, personal and group fit, and person and supervisor fit. In order to make up for the insufficiency in defining the environment in the past research, this research will incorporate the four 
fit concepts of person and organization fit (P-E fit), person and group fit (P-G fit), person and job fit (P-J fit), and person and supervisor fit (P-S fit) simultaneously, and further analyze the strength of weakness of each variable on retention tendency, proposing a more comprehensive fit research framework. 6

\section{LITERATURE REVIEW}

The Effect of Person-Organization Fit on Retention Tendency

The Attraction-Selection-Attrition (ASA) has been prevalently applied to person and organization fit (Schneider, 1987). The ASA cycle model describes that an organization attracts people of similar type, through selection to select personnel with the same values or attributes as the organization. One who does not possess values or attributes similar to organization will be eliminated or resigned. This argument is consistent with the long-term empirical conclusions, which is based on $\mathrm{P}-\mathrm{O}$ fit questionnaires at three different stages and P-O fit varies over time. The longer the person stays in the organization, the more the person and the organization fit are, and the higher the degree of fit (Roczniewska, Retowski, \& Higgins, 2018; Saks \& Ashforth, 1997). This also corresponds to results of the previous research; P-O fit at different stages is negatively related to resignation tendency (Chatman, 1989). The previous research showed that job embeddedness is related to resignation tendency (Mitchell, Holtom, Lee, Sablynski, \& Erez, 2001). Job embeddedness includes connection, fit and sacrifice, which indicates $\mathrm{P}-\mathrm{O}$ fit is one of the dimensions in the resignation tendency. Still more previous studies also proposed one of the reasons for person to leave the organization due to P-O fit deficiency (Gooley, 2001); When new staff join the organization, the culture of the organization is not easy to be acknowledged, understood, or even not easy to be integrated into the organization group, the person will not possess the sense of belonging, they tend to leave the organization (Autry \& Daugherty, 2003). In addition to the above arguments, several scholars have pointed out that $\mathrm{P}-\mathrm{O}$ fit is significantly related to resignation tendency (Cable \& Judge, 1996; Lauver \& Kristof-Brown, 2001; Saks \& Ashforth, 1997).

There were some previous study contributing to retention tendency and P-O fit in addition to the literature on P-E fit affecting resignation tendency. In Chatman (1989) study suggested that organizational values are consistent with individual values, high P-O fit, affects personal values, extrarole behavior, and retention behavior (Chatman, 1989). P-O fit has a significant correlation with the retention tendency (Ruiz-Palomino, Martínez-Cañas, \& Fontrodona, 2013). Therefore, we can find that organizations and personnel are both pursuing a balance with each other. And those who retain in the organization are able to complement the organization. Based on these studies on correlation between person and organization fit on resignation tendency and the positive correlations of retention tendency, this study proposes the following hypothesis.

H1: Person-organization fit of $R \& D$ personnel is positively related to retention tendency.

\section{The Effect of Person-Group Fit on Retention Tendency}

In the previous research on teams, the nature of group members can be divided into heterogeneous and homogeneous (Campion et al., 1993), wherein, group homogeneity scholars, Weldon and Weingart (1993) considered that the higher the consistency of values and goals with group members, the better their performance. Accordingly, when members of the organization possess the same values, they shall possess a similar cognitive process. Group members have the same aspirations and persuasion in job tasks (Zheng, 1995). Further, the study argued that individual behaviors and attitudes were not determined by personality attributes and contextual constraints, but by the interaction of personality and context (Muchinsky \& Monahan, 1987). Incorporated the study, that the interaction between members and group can also predict the behavior of each other, strengthening the interpersonal trust (Chen, 2000). Hence, it can be inferred that when individuals possess consistent values with group members, individuals and groups show a high fitness, and individuals develop higher commitment to the group. Their retention tendency is higher, in turn minimizing the intention to leave; conversely, if the values of individuals and group members are very different, P-G fit is low, resulting in a low commitment to the group. And then individuals are less willing to retain in the group, easily to generate intentions to resign. Therefore, this study proposes the following hypothesis based on the above arguments:

H2: Person-Group Fit of R\&D personnel is positively related to retention tendency.

\section{The Effects of Person-Job Fit on Retention Tendency}

In the previous study proposed that a person completely perceives his abilities for other jobs, which shall enhance his employment competitiveness in the job market and enable him with more opportunities to select for other different job. However, the competent personnel is given less alternative job offer, which lead him to be more proactive in 
finding other job opportunities. In result, those with higher abilities have higher resignation tendency (Jackofsky \& Peters, 1983). Furthermore, the researchers conducted longterm analysis the fit of personal ability and job complexity. The study found that when a person's ability is higher than the current job complexity, he will have the intention to switch to a job with higher complexity; conversely, if a person's ability is lower than the current job complexity, then there will be a tendency to switch to a job with less complex than the current one (Wilk \& Sackett, 1996). With this switch model, the balance between person and job fit should be achieved, so a person will pursue the position with P-J fit. Therefore, the higher fit is, the higher the retention tendency is; conversely, the lower fit is, the lower the retention tendency is. In addition to the above arguments of P-J fit, still other study proposed the fitness of person and job from six aspects, including knowledge, skills, abilities, interests, job characteristics, and personality (Chuang \& Sackett, 2005); and there were also definition in the elements of P-J fit. Knowledge, skills and abilities can be used to measure the person to job fit (Chuang \& Lin, 2005). In addition, the study suggested that P-J fit as well as resignation tendency, job satisfaction, and organizational commitment are highly relevant (Kristof, 1996). Therefore, from the above relevant arguments, it can be known that regardless of the knowledge, skills, abilities, or other factors, when the degree of person and job fit is low, the person may generate the intention to leave. If the job does not fit in with its own abilities, it will result in poor performance, affecting retention tendency. This study proposes the following hypothesis:

H3: Person-job fit of R\&D personnel is positively related to retention tendency.

\section{The Effect of Person-Supervisor Fit on Retention Ten- dency}

The previous study indicated that the effects of direct supervisors and subordinates on the fitness of general values. It showed that the supervisor's compassion, achievement and competence are positively correlated with the P-S fit (Weiss, 1978); further, other studies pointed out that managers and their subordinates perceive similarities with each other, and they will rank each other with higher performance (Pulakos \& Wexley, 1983); still other study mentioned a trust relationship between supervisors and subordinates in the group; when entering maturity, their relationship will be based on responsibility, trust and mutual obligations (Graen \& Scandura, 1987); when operators and supervisors have consistent job values, the employee satisfac- tion and organizational commitment are higher (Meglino, Ravlin, \& Adkins, 1989). In addition, a research suggested that when two individuals perceive each other to be similar, they will increase their attractiveness and are more likely to develop relationships with each other (Grant, 1993).

From the above research, it can be inferred that when supervisors and subordinates have consistency in values, such as personality and background, they have high trust in each other. With their similarity, the individual and the supervisor highly compatible, so at work, they have a high sense of trust, communicating without difficulty and less conflicts between them. Therefore, it is less likely to cause intention to leave the organization, resulting in high retention tendency; conversely, if the values of the supervisors and the subordinates are different, at work, there is no trust between the two, communication is poor and they are prone to conflicts. It might cause inclination of retention tendency. This study proposes the following hypothesis based on the above inferences:

H4: Person-supervisor fit of R\&D personnel is positively related to retention tendency.

\section{The Effect of Person-Organization, Person-Group, Person-Job and Person-Supervisor Fits of Retention Tendency}

The previous discussion all pointed out that $\mathrm{P}-\mathrm{O}$ fit has a significant effect on retention tendency (Chuang \& Lin, 2005; Ruiz-Palomino et al., 2013); person and group contexts have an interactive effect, so it can be inferred that P-G fit has a significant effect on retention tendency (Muchinsky \& Monahan, 1987); P-J fit also affects the tendency of person to leave the job, so it can be inferred that they have positive correlation with retention tendency (Lauver \& KristofBrown, 2001; Wilk \& Sackett, 1996); supervisors and subordinates have similar values, and they will have a higher degree of fit or commitment. Therefore, it can be inferred that there are significant correlation between P-S fit and retention tendency (Meglino et al., 1989; Weiss, 1978).

Xie (2005) pointed out that when measuring multidimensional fits of a person, there is an interaction effect, so the relevant fits can be included in the study to confirm whether there is a multiplier effect or a reduction effect in different fits. In addition, Kristof (1996) also pointed out that P-O fit, P-G fit and P-J fit shows different manifestations of person and environment fit. Based on the above inference, this study will explore the retention tendency through multi-dimensional fits, and discuss whether there are variables that have the most significant effect on retention tendency and how significant the effect is, so the following hy- 
pothesis is proposed:

H5: The person-organization, person-job and personsupervisor fits have significantly positive effects on the re- tention tendency.

\section{RESEARCH METHODOLOGY}

The research of framework as follows:

FIGURE 1. Research framework

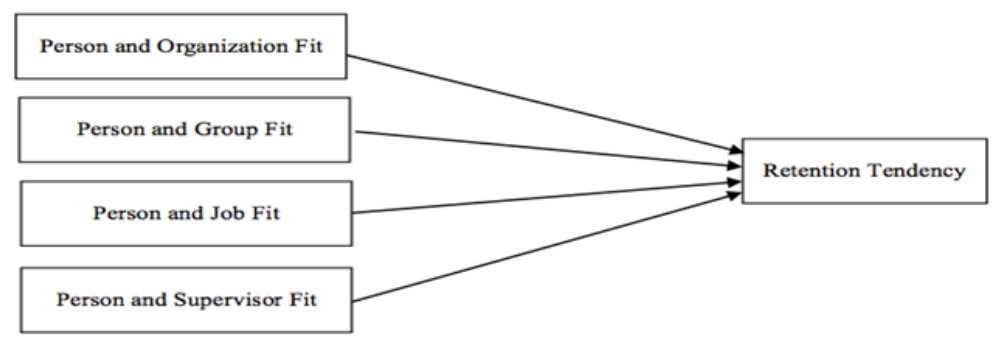

\section{Sample and Procedure}

For the purpose of this research, our target population is the R\&D department personnel listed in the Taiwan Semiconductor Industry Association research, requesting development personnel of the high-tech company to answer the questionnaire. There were 15 companies selected for sampling, and a total of 300 questionnaires were sent out. Totally 216 questionnaires returned from the samples were valid, a response rate of $72 \%$. In order to avoid the subject's defensive mentality and reduce bias caused by social expectations, the questionnaires are conducted anonymously. Every formal questionnaire was sent with a cover letter and a self-addressed stamped envelope. All questionnaires were collected within two months after the distribution.

\section{Instruments}

For the empirical research data collection, our questionnaires are all based on the scale developed by foreign scholars. Some experts from the academic and practical field are invited to conduct the review. It is hoped that the questionnaire will be more appropriate through the modification of words and phrases, and it can be closer to the job content of R\&D staff. The items to be answered in the questionnaires are "Person and Organization Fit", "Person and Group Fit", "Person and Job Fit", "Person and Supervisor Fit", and "Retention Tendency" respectfully, and "Personal Profile" and "Negative Sentiment" are used as the control variables of this study. This study will examine the constructed validity and reliability of the scale by CFA (known as CFA). The following is a sequence of description of the scales used.

\section{Person and organization fit scale}

This scale recited the concepts proposed by Saks and Ashforth (1997) and there are four questions in total. The measurement is mainly based on the fit perspective of values and personality characteristics, exploring the effect of P-O fit on retention tendency. Ratings are provided on the Likert's five-point scale format, which is given 1 to 5 points according to the five levels of "Very Disagree", "Disagree", "No opinion", "Agree" and "Very Agree". The higher score indicates that the individual's P-O fit is higher. Cronbach's $\alpha$ value of the overall scale was .87, higher than the acceptable value of .70, indicating that the internal consistency of the scale was good. In the comprehensive model verification results, the compositional reliability of P-O fit is .87 , which is greater than the standard value of 60 recommended by Fornell and Larcker (1981), indicating that the scale has good internal consistency. Furthermore, the average variation of .70 in sampling also meets .50 standard, recommended by Fornell and Larcker (1981), so the scale has a certain level of convergence validity.

\section{Person and group fit scale}

The Salvaggio (2003) P-G fit scale is adopted in the current research, which is revised from the Person and Organization scale developed by Saks and Ashforth (1997). The original scale measures the fit of person to organization. The designed item can be applied to measure different organization fit patterns. Therefore, the original question, number of questions and scale are maintained. Only the fit object is changed to the group, and the total number of question is in 4 items. The measurement is mainly based on the fit in values and group characteristics, and explores the effect of $\mathrm{P}-\mathrm{G}$ fit on retention. The response format is a 5-point Likert scale ranging from "strongly disagree" to "strongly agree". The higher the score counts, the higher P-G fit is. Cronbach's $\alpha$ value of the overall scale was .90, higher than the acceptable value of .70, indicating good internal consistency. In the comprehensive model verification results, the compositional reliability of P-G fit is .90 , which is greater than the standard value of 60 recommended by Fornell and Larcker 
(1981), indicating that the scale has good internal consistency. Furthermore, the average variation of 70 in sampling also meets .50 standard, recommended by Fornell and Larcker (1981), so the scale has a certain level of convergence validity.

\section{Person and job fit scale}

The scale is recited the concepts proposed by Saks and Ashforth (1997), there are four questions in total. The measurement is mainly based on the fit of supply and demand of personal ability, exploring the effect of P-J fit on retention. Likert's five-point scale format is provided ratings, which is given 1 to 5 points according to the five levels of "Very Disagree", "Disagree", "No opinion", "Agree" and "Very Agree". The higher score indicates that the individual's P-J fit is higher. Cronbach's $\alpha$ value of the overall scale was .82, higher than the acceptable value of .70, indicating that the internal consistency of the scale is good. In the comprehensive model verification results, the compositional reliability of person and job fit is .82, which is greater than the standard value of 60 recommended by Fornell and Larcker (1981), indicating that the scale has good internal consistency. Furthermore, the average variation of .64 in sampling also meets .50 standard, recommended by Fornell and Larcker (1981), so the scale has a certain level of convergence validity.

\section{Person and supervisor fit scale}

The Salvaggio (2003) P-S fit scale is adopted is this current research, which is revised from the Person and Organization Scale developed by Saks and Ashforth (1997). The original scale measures the fit of person to organization. The designed item can be applied to measure different organization fit patterns. Therefore, the original question, number of questions and scale are maintained. Only the fit object is changed to the supervisor, and the total question is in 4 items. The measurement is mainly based on the fit in values and supervisor characteristics, exploring the effect of P-S fit on retention. The response format is a 5-point Likert scale ranging from "strongly disagree" to "strongly agree". The higher the score counts, the higher P-S fit is. Cronbach's $\alpha$ value of the overall scale was .93, higher than the acceptable value of .70 , indicating that the internal consistency of the scale is good. In the comprehensive model verification results, the compositional reliability of person and supervisor fit is .93, which is greater than the standard value of .60 recommended by Fornell and Larcker (1981), indicating that the scale has good internal consistency. Furthermore, the average variation of 84 in sampling also meets . 50 stan- dard, recommended by Fornell and Larcker (1981), so the scale has a certain level of convergence validity.

\section{Retention tendency scale}

This study intends to explore the retention tendency of R\&D personnel, so there is no need to use the negative concept of resignation for the retention tendency questionnaire. Accordingly, Flood, Turner, Ramamoorthy, and Pearson (2001) positive question are used to measure the retention tendency of the person, and the total number of question is 3 items. Likert's five-point scale format is used, which is given 1 to 5 points according to the five levels of "Very Disagree", "Disagree", "No opinion", "Agree" and "Very Agree". The high score indicates one's retention tendency is high. Cronbach's $\alpha$ value of the overall scale was .87, higher than the acceptable value of .70, indicating good internal consistency. In the comprehensive model verification results, the compositional reliability of person and supervisor fit is .87 , which is greater than the standard value of .60 recommended by Fornell and Larcker (1981), indicating that the scale has good internal consistency. Furthermore, the average variation of .92 in sampling also meets .50 standard, recommended by Fornell and Larcker (1981), so the scale has a certain level of convergence validity.

\section{Control variables}

In the current research aiming to realize the effect of personal factors on the concept of resignation tendency and retention tendency, the two perspectives of the objective (Black \& Stevens, 1989), the previous research point out that gender, age, education, marital status, tenure, and the number of employees had effect on resignation intentions (Khatri, Fern, \& Budhwar, 2001; Ghiselli, La Lopa, \& Bai, 2001). Therefore, we take gender, age, education level, marital status and tenure as control variables to avoid possible adjustment effects caused by exogenous variables. Because this research is using R\&D personnel's self-assessment to fill the questionnaires, the subject is measured by his personal perception. It is easy to be affected by psychological factors and may generate Common Method Variance (CMV). In order to reduce the common method variance issue, this study incorporates negative emotion into control variables (Peng, Y.C., \& Lin, 2006). The negative emotion scale adopted the research of Wu and $\mathrm{Hu}$ (2009), selected the scale of negative perspective emotion, rating by Likert five-point scale model. Using "always have this feeling", "often have this feeling", "sometimes have this feeling", "rarely have this feeling", "never feel this way" as the five different level, the five levels are given 1 to 5 points respectively to 
measure the state of the negative sentiment level of the subject. Due to controlling the negative emotion status quo of the past week, George and Zhou (2002)'s guidance terms are provided in the research.

\section{Comprehensive module fit}

In order to confirm whether all items can effectively measure each dimension. We conducted CFA to examine the quality of the measurement, aiming at P-O fit, P-G fit, P-J fit,
P-S fit and retention tendency. The results are shown in Table 1 . The load of each item is between .30 and .88, which is in accordance with the standard .30 or above (Hair, Black, Babin, Anderson, \& Tatham, 2006). In terms of model fit scale, for this research, the CFI of $=.92$, NNFI $=.91$, SRMR $=$ .06 , and RMSEA $=.08$. Based on the above-mentioned other fit scale, in general, the comprehensive fit still reaches the acceptable range (Cable \& Judge, 1996; Bentler \& Bonett, 1980; Hair et al., 2006).

TABLE 1. Comprehensive confirmatory factor analysis

\begin{tabular}{|c|c|c|c|c|c|}
\hline Facet & No. & Question & Load Factor & & \\
\hline \multirow[t]{4}{*}{ Organization Fit } & 01 & My personal values are very similar to the company's values. & .81 & & \\
\hline & 02 & My personality matches the company's image. & .78 & & \\
\hline & 03 & The company will make its best to satisfy my needs at work. & .71 & & \\
\hline & 04 & I consider my current company is very suitable for me. & .85 & & \\
\hline \multirow[t]{4}{*}{ Group Fit } & 01 & My group values are similar to my personal values. & .87 & & \\
\hline & 02 & My personality and group attributes are similar. & .85 & & \\
\hline & 03 & My group enable to satisfy my needs. & .84 & & \\
\hline & 04 & My group and I are matching. & .77 & & \\
\hline \multirow[t]{4}{*}{ Job Fit } & 01 & $\begin{array}{l}\text { My knowledge, skills, abilities and work attributes that I belong to match } \\
\text { very well. }\end{array}$ & .65 & & \\
\hline & 02 & My job can satisfy my interest. & .82 & & \\
\hline & 03 & My job and I are compatible. & .90 & & \\
\hline & 04 & R\&D work is the ideal job type I want. & .55 & & \\
\hline \multirow[t]{4}{*}{ Supervisor Fit } & 01 & My supervisory and I have very similar values. & .89 & & \\
\hline & 02 & My personality and my supervisor characteristics are very similar. & .82 & & \\
\hline & 03 & My supervisor can satisfy my needs. & .89 & & \\
\hline & 04 & My supervisor and I are very compatible. & .91 & & \\
\hline \multirow[t]{3}{*}{ Retention } & 01 & $\begin{array}{l}\text { Even the company's current operating conditions are not good. I still don't } \\
\text { want to change companies. }\end{array}$ & .85 & & \\
\hline & 02 & Even if other companies offer me more salary, I will not change jobs. & .78 & & \\
\hline & 03 & I want to be with this company for long term. & .85 & & \\
\hline \multirow[t]{5}{*}{ Negative Sentiment } & 01 & Distressed. & .58 & & \\
\hline & 02 & Annoying. & .57 & & \\
\hline & 03 & Frightened. & .86 & & \\
\hline & 04 & Scared & .88 & & \\
\hline & & Fit Indicators of the Model & & & \\
\hline$\chi 2 / \mathrm{df}$ & df & CFI & NNFI & SRMR & RMSEA \\
\hline 2.28 & 215 & .92 & .91 & .06 & .08 \\
\hline
\end{tabular}

\section{Data Analyses}

Before proceeding data analysis, invalid questionnaires, such as: incomplete data, unmatched, and consistent answers, were removed from our data. SPSS was used for descriptive statistical analysis, correlation analysis, variance analysis, and hierarchical regression analysis, and use AMOS for confirmatory factor analysis.

\section{RESULTS}

In order to have better understanding the relationship among variables, this research used Pearson's product difference correlation analysis to examine the degree of correlation among variables. According to the degree of correlation, it can be known that person and organization in- dicate a significant positive correlation with retention tendency $(r=.63, p<.001)$; person and group indicate a significant positive correlation with the retention tendency $(r$ $=.52, p<.001$ ); person and job indicate a significant positive correlation with retention tendency $(r=.54, p<.001)$; person and supervisor indicate a significant positive correlation with retention tendency $(r=.55, p<.001)$. It is consistent with the hypotheses of this research that the person and organization, person and group, person and job, and person and supervisor fits of the R\&D personnel are positively correlated to retention tendency. The scholars Hair et al. (2006) pointed out that if the correlation coefficient between variables is above .80 , it indicates that there is a 
problem of collinear. The correlation coefficients between each variable in this research are all less than .80. There- fore, it is not serious for us to concern about problems of multi-collinear.

TABLE 2. Retention tendency and variance analysis within company

\begin{tabular}{llllll}
\hline \hline & SS & df & MS & $\boldsymbol{F}$ & Significance \\
\hline Between Groups & 40.34 & 14.00 & 2.88 & 4.05 & .000 \\
Within Group & 143.07 & 201.00 & .71 & & \\
Total & 183.41 & 215.00 & & & \\
\hline \hline
\end{tabular}

Note:SS:Summation of Square MS: Average Square

We examined the hypotheses on the effect of P-O fit, P-J fit, $\mathrm{P}-\mathrm{S}$ fit of the R\&D personnel on the retention tendency, using the variance analysis and the hierarchical regression analysis. The results of the variance analysis are shown in Table 2. The significant variance of retention tendency $(p<.001)$ in a company, indicating that this research is not affected by in- stitutional effects. However, the $F$ value is significantly different, but the post-test is not significant. It may occur at the critical value, indicating that the difference in retention tendencies of different companies should be small, so it will not have a significant effect on the research.

TABLE 3. Effect of person and organization, group, job, and supervisor fits on retention tendency

\begin{tabular}{|c|c|c|c|c|c|c|}
\hline \multicolumn{7}{|l|}{ Dependent Variable: Retention Tendency } \\
\hline Predict Variable & Model 1 & Model 2 & Model 3 & Model 4 & Model 5 & Model 6 \\
\hline \multicolumn{7}{|l|}{ Control Variable } \\
\hline Gender & .03 & .10 & .10 & .03 & .11 & $.11^{*}$ \\
\hline Age & .15 & .11 & $.18^{* * *}$ & .11 & $.21^{* * *}$ & $.14^{*}$ \\
\hline Education Level & -.06 & -.08 & -.10 & -.16 & -.12 & $-.12^{*}$ \\
\hline Marital Status & .08 & -.00 & .05 & -.00 & .01 & -.03 \\
\hline Tenure in Company & -.08 & .05 & -.03 & -.03 & -.14 & -.02 \\
\hline Tenure in R\&D & -.05 & -.01 & -.03 & .01 & .03 & .03 \\
\hline Company Headcount & -.09 & .03 & -.05 & -.03 & -.01 & .05 \\
\hline R\&D Headcount & .07 & .04 & .07 & .02 & .02 & .01 \\
\hline Negative Sentimen & -.02 & .00 & .00 & .06 & .01 & .03 \\
\hline \multicolumn{7}{|l|}{ Independent Variable } \\
\hline Organization Fit & & $.65^{* * *}$ & & & & $.40^{* * *}$ \\
\hline Group Fit & & & $.54^{* * *}$ & & & .02 \\
\hline Job Fit & & & & $.55^{* * *}$ & & $.16^{*}$ \\
\hline Supervisor Fit & & & & & $.58^{* * *}$ & $.29^{* * *}$ \\
\hline$R^{2}$ & .01 & $.40^{* * *}$ & $.30 * * *$ & $.28^{* * *}$ & $.33^{* * *}$ & $.50 * * *$ \\
\hline$\Delta R^{2}$ & & $.38^{* * *}$ & $.28^{* * *}$ & $.26^{* * *}$ & $.31^{* * *}$ & $.47^{* * *}$ \\
\hline$F$ & 1.35 & $135.67^{* * *}$ & $86.34^{* * *}$ & $79.93^{* * *}$ & $97.96^{* * *}$ & $50.16^{* * *}$ \\
\hline
\end{tabular}

Note:1. Gender is treated as a virtual variable; male is 1 , and female is 0.2 . Marital status is treated as a virtual variable; single is 1 , married is 0.3. Age, service, and tenure are all treated as virtual variables. 4. The values in the table are standardized $\beta$ values. $5 .{ }^{*} p<.05,{ }^{* *} p<.01,{ }^{* * *} p<.001$

The results of the hierarchical regression analysis are shown in Table 3, testing all our hypotheses. From the model 2, it can be seen that the P-O fit of the R\&D personnel is significantly positive related to retention tendency $(\beta=$ $.65, p<.001$ ), so our hypothesis 1 is supported; from model 3 , it can be seen that that $\mathrm{P}-\mathrm{G}$ fit of $\mathrm{R} \& \mathrm{D}$ personnel is significantly positive related to retention tendency $(\beta=.54, p$
$<.001$ ), so our hypothesis 2 is supported; from model 4, it can be seen that P-J fit of the R\&D personnel is significantly positive related to retention tendency $(\beta=.55, p<.001)$, so our hypothesis 3 is supported; from model 5 , it can be seen that P-S fit of the R\&D personnel is significantly positive related to retention tendency $(\beta=.58, p<.001)$, so our hypothesis 4 is supported. In model 6 , the multi-dimensional 
fits of R\&D personnel shows that P-O fit has a positive effect on retention tendency in multi-dimensional fit $(\beta=.40, p<$ .001); P-G fit has no positive effect on retention tendency in multi-dimensional fit ( $\beta=.02, p>.05$ ); P-J fit has a positive effect on retention tendency in multi-dimensional fit $(\beta=$ $.16, p<.05)$; P-S fit a positive effect on retention tendency in multi-dimensional fit $(\beta=.29, p<.001)$, and $R$ square variance $\left(\Delta R^{2}=.47, p<.001\right)$ indicates that during multidimensional fits, there is a significant correlation with retention tendency. Therefore, our hypothesis 5 is supported.

\section{DISCUSSION}

When reviewing the effect of multi-dimensional fit on retention tendency, the $\beta$ value of $P-G$ fit is not reach the significant level, and P-O fit, P-J fit and P-S fit reach the significant level. This indicates that under multi-dimensional fit, P-G fit has no significant positive effect on retention tendency, which is contrary to the direction of this research. This research speculates that there is an interaction effect among multi-dimensional fits (Xie, 2005). Therefore, the effect of P-G fit on retention tendency is affected by other fits, weakening its effect, resulting in only personorganization, person-job and person-supervisor fits have significantly positive effects on the retention tendency.

\section{Conclusion}

To summarize from our findings, the person and organization, group, job, and supervisor fits of the R\&D personnel are significantly positive related to retention tendency. As our prediction, when organizations and personnel are both pursuing a balance with each other and R\&D personnel retaining in the organization are able to complement the organization. Person-organization fit of the R\&D personnel is positively related to retention tendency. When the R\&D personnel possess consistent values with group members and individuals develop higher commitment to the group, individuals are willing to retain in the group. Person-group fit of the R\&D personnel is positively related to retention tendency. When the job does fit in with abilities of the R\&D personnel, it will result in good performance, affecting retention tendency. Person-job fit of the R\&D personnel is positively related to retention tendency. When supervisors and subordinates have consistency in values, they have high trust in each other. With their similarity, the R\&D personnel and their supervisors highly compatible, communicating without difficulty and less conflicts between them. Therefore, it is less likely to cause intention to leave the organization, resulting in high retention tendency. Personsupervisor fit of the R\&D personnel is positively related to retention tendency.

\section{IMPLICATIONS}

1. Focus on P-O fit of R\&D personnel to enhance retention tendency Barney (1991) pointed out that the human capital of an organization is recognized as an important source to maintain competitive advantage (Barney, 1991). Person and organization fit should be enhanced, including the values, personality traits, and organizational culture of the R\&D personnel. The organization can continuously convey corporate culture, vision and goals, organizational philosophy and values through town hall meeting, internal websites, bulletin boards, and corporate internal propaganda channel. In addition, through various activities including new hire training, corporate sports, family day, which enable the organizational culture and values continuously affecting personnel in an imperceptible influence way. Creating employees and organizations a common living community, and strengthening the fitness of organization increase employee retention rate. For the new hired staff, paying more attention to them for their understanding the real meanings of organization cultural, establishing organizational identity. They may feel that the organization attach to them so as to gain a sense of belonging to the organization and to enhance the retention tendency.

2. Focus on P-G fit of R\&D personnel to enhance retention tendency Retention tendency of R\&D personnel is affected by their own perceived perspective and high fitness with current group members. There are many influential factors, the need for belonging, the sense of security, the job position and the role in the group, as well as the interpersonal relationship between members, whether they respect and care among one and other, which interact and affect the strength of group fit. Therefore, it is necessary to establish respect, tolerance and encouragement in different opinions, so that the workplace is open and trusting, which enable personnel work in the group with a peace of mind and feel reassured. In daily life, we suggest carrying out multi-respect related courses and organizing activities (departmental boot camp or group competitions) to shape the group culture, cultivate tacit teamwork and common values, and demonstrate the benefits of teamwork. In the new hired R\&D personnel, it is better to assign appropriate guide to help them fit into the group culture and endorse their group identity quickly. Due to increasing P-G fit, retention tendency of R\&D personnel will be high.

3. Focus on P-Job fit of R\&D personnel to enhance retention tendency Individuals have different fitness to their positions because of their needs and abilities. However, to 
maintain high fitness, the needs, abilities and willingness of R\&D personnel should be thoroughly considered. Therefore, enterprises should fully enhance the education and training in R\&D professional knowledge, and also encourage employee to participate in professional seminars, and regularly hold R\&D meetings or host new product and technology conferences. Due to providing opportunities to enhance their new knowledge and skills, R\&D personnel can maintain high P-J fit so as to improve retention tendency. In addition to focusing on ability enhancement, enterprises should also focus on the needs of R\&D personnel so as to avoid perceived bias and lower the retention tendency. For example, an open and transparent promotion or reward system (such as: patent bonus, research and development proposal bonus, research and development performance bonus) can encourage R\&D personnel to constantly challenge themselves to innovate new technology. The previous study showed that there are four stages in the professional career for technical staff, and each stage has different needs, so enterprises must pay more attention to the career development and planning of R\&D personnel (Brislin, 1980). In order to reduce employee's over qualified perception of the position, it is possible to increase the diversity of work content through the internal rotation mechanism, so that employees can continue to self-improve and grow, as well as accelerate one's experiences of different job functions (Lin \& Hu, 2009). It also gives more opportunities for R\&D personnel to develop and show their talents in various fields. Through R\&D personnel continuously satisfying the need for self-challenge, it is possible to maintain high P-J fit, thereby enhancing retention tendency. In the new hired, R\&D personnel, in addition to giving effective training courses, assigning challenging tasks to create a sense of job accomplishment improves their retention tendency.

4. Focus on P-S fit of R\&D personnel to enhance retention tendency In order to strengthen the comprehensive fitness between the self-sense of staff and supervisors, and to improve the retention tendency, enterprise should strengthen leadership ability of the supervisor and improve their management skills through the managerial curriculum; for example, to enhance the communication skills. Good communication methods establish effective communication channels and opportunities to reduce misunderstandings between subordinates and supervisors. For advocating corporate ethics, supervisors should encourage and care about employees. When employees feel support and good grace from the supervisors, they are easily to accept their leadership. For example, providing more chances for subordinates to participate in important project or giving them more powers and responsibilities make the subordinates feel the attention of the supervisors. Through benign interactions, P-S fit should be enhanced and improve retention tendency. In new hired R\&D personnel, supervisors should understand the needs of newcomers, giving them timely attention and encouraging them from time to time, so that newcomers enjoy the work friendship and enhance retention tendency.

5. Focus on person and organization, group, job, and supervisor fits of R\&D personnel to enhance retention tendency. In order to strengthen the fit of person to organization, group, job and supervisor, so as to improve the retention tendency, enterprises should strengthen fitness in multi-dimensions. No matter through the previous description on establishment of the organizational culture, the formation of a group atmosphere, the matching of job abilities, and the strengthening of executive leadership styles, it is also possible to adopt stay-interview to understand the factors if R\&D personnel can retain. With human resources strategies, organizations strengthen and enhance fitness to improve retention tendency.

The limitations of the study are as follows:

1. Effect on cross-cultural variation

This research uses the scales developed by foreign experts and scholars. Due to the foreign scales designed in accordance with western cultural context, it is different from the eastern cultural context. Therefore, when translating measures and conducting survey, it is easy to have a crossculture difference due to the semantics difference in cultures. In order to reduce the cross-cultural differences caused by translation and implementation, this research uses back translation method (Brislin, 1980) to translate the original text into Chinese, presenting the content of the questionnaire in a concise and clear sentence, and requesting review by experts and scholars in the academic and practical area for suggesting and adjusting the wording (Podsakoff, MacKenzie, Lee, \& Podsakoff, 2003).

\section{Common Method Variance}

The data collection of this research is based on self-answer the questionnaires of R\&D personnel. The subject is measured by one's own consciousness. It tends to cause a tendency to classify or be consistent in processing the message, or the subject is affected by psychological factors when answering the question. A CMV issue should be concerned. In order to reduce the impact of CMV on the research results and to prevent bias from unclear questions, using part1 and part2 instead of the measured variables to avoid being affected by the social desirability. It may affect the tendency to answer the questionnaire due to the knowledge of the 
variable name, retaining the true feelings, creating the possibility of deception. Finally, R\&D personnel were tested anonymously to reduce the defense mentality in order to correct the correctness, and the research applied negative sentimental into the control variables (Peng et al., 2006) to reduce the common method variance issue.

3. Verifying the retention rate

Due to the fact that companies regard retention rate or turnover rate as internal confidential and critical information, it is not disclosed to public easily. This research is hard to collect the actual retention rate of each high-tech industry for review and comparison, so the verification is conducted on the basis of information provided by our samples.

Following recommendations are given for future:

1. Applicability to high-tech industries

According to the criteria specified by the Ministry of Finance, R.O.C, the state's high-tech industry is classified into manufacturing of power and electronic device industry (excluding wire and cable, light bulbs, illumination device, and batteries), chemical materials industry, machinery and equipment industry (excluding woodworking machinery, mining machinery and equipment), transportation equipment industry (excluding auto parts, bicycles and parts, other transportation equipment and parts), chemical industry (excluding coating materials, paints, Chinese medicine, cleaning supplies and cosmetics) and precision equipment industry. In Taiwan, the high-tech industry is concentrated in the electronics industry; in general, the electronics industry includes the communications industry, the information industry, the semiconductor industry, the electronic component industry, the consumer electronics industry, the optoelectronics and instrumentation industries. This study uses samples only adopting semiconductor relevant industries in Taiwan. Accordingly, whether the conclusions of this research are applicable to the overall high-tech industry or not still needs further validation. Therefore, it is recommended that follow-up researchers can explore extensively in different high-tech industries.

\section{Multiple measurement objects}

This research is targeted on the R\&D personnel in the hightech industry. Although R\&D personnel are critical assets of a company, yet there are still other key professionals in the enterprise. Therefore, it is recommended that follow-up researchers can expand to different professionals, and thus the results can be used to compare with of this research, and enable enterprises to formulate a comprehensive human resource management retention strategy.

3. Incorporate longitudinal analysis into research design This research takes a cross-section analysis approach. However, the relationship of the fits and retention tendency among person and organization, group, job and supervisor may be affected over time. Therefore, it is recommended that the follow-up researchers can incorporate longitudinal analysis into the research design, which should more accurately reflect P-O fit, P-G fit, P-J fit and P-S fit on retention tendency. The phenomenon of variance shall enable the research discussion be more abundant.

\section{REFERENCES}

Autry, C. W., \& Daugherty, P. J. (2003). Warehouse operations employees: Linking person-organization fit, job satisfaction, and coping responses. Journal of Business Logistics, 24(1), 171-197. doi:https://doi.org/10.1002/j.2158-1592.2003 .tb00036.x

Barney, J. (1991). Firm resources and sustained competitive advantage. Journal of Management, 17(1), 99-120. doi:https:// doi.org/10.1177/014920639101700108

Bentler, P. M., \& Bonett, D. G. (1980). Significance tests and goodness of fit in the analysis of covariance structures. Psychological bulletin, 88bentler1980significance(3), 588-606. doi:https://doi.org/10.1037//0033-2909.88.3.588

Black, J. S., \& Stevens, G. K. (1989). The influence of the spouse on expatriate adjustment and intent to stay in overseas assignments. In Academy of Management Proceedings, New York, NY.

Brislin, R. W. (1980). Translation and content analysis of oral and written materials. Methodology, 5(8), 389-444.

Cable, D. M., \& Judge, T. A. (1996). Person-organization fit, job choice decisions, and organizational entry. Organizational Behavior and Human Decision Processes, 67(3), 294-311. doi:https://doi.org/10.1006/obhd.1996.0081

Campion, M. A., Medsker, G. J., \& Higgs, A. C. (1993). Relations between work group characteristics and effectiveness: Implications for designing effective work groups. Personnel Psychology, 46(4), 823-847. doi:https://doi.org/10.1111/ j.1744-6570.1993.tb01571.x

Chatman, J. A. (1989). Matching people and organizations: Selection and socialization in public accounting firms. In Academy of Management Proceedings, New York, NY. 
Chen, J. (2000). Relationship and interpersonal relationship quality: The mediating effect of subjective fit and the adjustment effect of relationship type (Unpublished master's thesis). Department of Psychology, National Taiwan University, Taipei, Taiwan.

Chuang, A., \& Lin, H. (2005). An investigation of the effect of person-environment fit on work attitudes and behaviors. Taiwan Academy of Management Journal, 5(1), 123-148.

Chuang, A., \& Sackett, P. R. (2005). The perceived importance of person-job fit and person-organization fit between and within interview stages. Social Behavior and Personality: An International Journal, 33(3), 209--226. doi:https:// doi.org/10.2224/sbp.2005.33.3.209

Edwards, J. R. (1991). Person-job fit: A conceptual integration, literature review, and methodological critique. New York, NY: John Wiley \& Sons.

Fitz-enz, J. (1997). It's costly to lose good employees: Workforce, 50. Cambrideg, MA: Addison Welsley.

Flood, P. C., Turner, T., Ramamoorthy, N., \& Pearson, J. (2001). Causes and consequences of psychological contracts among knowledge workers in the high technology and financial services industries. International Journal of Human Resource Management, 12(7), 1152-1165. doi:https://doi.org/10.1080/09585190110068368

Fornell, C., \& Larcker, D. F. (1981). Structural equation models with unobservable variables and measurement error: Algebra and statistics. Los Angeles, CA: SAGE Publications.

George, J. M., \& Zhou, J. (2002). Understanding when bad moods foster creativity and good ones don't: The role of context and clarity of feelings. Journal of Applied Psychology, 87(4), 687-697. doi:https://doi.org/10.1037//0021-9010.87.4.687

Ghiselli, R. F., La Lopa, J. M., \& Bai, B. (2001). Job satisfaction, life satisfaction, and turnover intent: Among food-service managers. Cornell Hotel and Restaurant Administration Quarterly, 42(2), 28-37. doi:https://doi.org/10.1177/ 0010880401422002

Gooley, T. B. (2001). How to keep good people. Logistics Management and Distribution Report Radnor, 40, 55-60. doi: https://doi.org/10.1109/iemc.2002.1038490

Graen, G. B., \& Scandura, T. A. (1987). Toward a psychology of dyadic organizing. Research in Organizational Behavior, 3(7), 34-51.

Grant, P. R. (1993). Reactions to intergroup similarity: Examination of the similarity-differentiation and the similarityattraction hypotheses. Canadian Journal of Behavioural Science/Revue canadienne des sciences du comportement, 25(1), 28-35. doi:https://doi.org/10.1037/h0078789

Hair, J. F., Black, W. C., Babin, B. J., Anderson, R. E., \& Tatham, R. L. (2006). Multivariate data analysis. Upper Saddle River, NJ: Pearson Prentice Hall.

Hong, C., \& Lin, Z. (1991). Research on labor mobility in Taiwan. Journal of Enterprise Bank, 15(4), 1-22.

Jackofsky, E. F., \& Peters, L. H. (1983). The hypothesized effects of ability in the turnover process. Academy of Management Review, 8(1), 46-49. doi:https://doi.org/10.2307/257166

Khatri, N., Fern, C. T., \& Budhwar, P. (2001). Explaining employee turnover in an Asian context. Human Resource Management Journal, 11(1), 54-74. doi:https://doi.org/10.1111/j.1748-8583.2001.tb00032.x

King, J. M. (2016). Dubai wins: A content analysis of global media coverage of the 2020 world exposition bidding process using nation branding theory. International Journal of Business and Administrative Studies, 2(6), 201-211. doi:https:// doi.org/10.20469/ijbas.2.10005-6

Kolenko, T., \& Aldag, R. (1989). Congruence perceptions and managerial career/work outcomes: An exploratory analysis. In Meeting of the National Academy of Management, New York, NY.

Kraut, A. I. (1975). Predicting turnover of employees from measured job attitudes. Organizational Behavior and Human Performance, 13(2), 233-243. doi:https://doi.org/10.1016/0030-5073(75)90047-1

Kristof, A. L. (1996). Person-organization fit: An integrative review of its conceptualizations, measurement, and implications. Personnel Psychology, 49(1), 1-49. doi:https://doi.org/10.1111/j.1744-6570.1996.tb01790.x

Lauver, K. J., \& Kristof-Brown, A. (2001). Distinguishing between employees' perceptions of person job and personorganization fit. Journal of Vocational Behavior, 59(3), 454-470. doi:https://doi.org/10.1006/jvbe.2001.1807

Li, J., \& Chen, Y. (1999). Research on the correlation between high-tech industry characteristics, job pressure, job satisfaction and turnover intentions-taking the R\&D and engineering technicians of high-tech manufacturers in Hsinchu as an example. Journal of Human Resources, 11(6), 93-116. 
Lin, L., \& Hu, M. (2009). The interference effect of job characteristics and trust and leadership style on job performancetaking Taiwan's investment industry as an example. Journal of Enterprise Management, 82(1), 48-88.

Meglino, B. M., Ravlin, E. C., \& Adkins, C. L. (1989). A work values approach to corporate culture: A field test of the value congruence process and its relationship to individual outcomes. Journal of Applied Psychology, 74(3), 424-432. doi: https://doi.org/10.1037//0021-9010.74.3.424

Mitchell, T. R., Holtom, B. C., Lee, T. W., Sablynski, C. J., \& Erez, M. (2001). Why people stay: Using job embeddedness to predict voluntary turnover. Academy of Management Journal, 44(6), 1102-1121. doi:https://doi.org/10.5465/3069391

Muchinsky, P. M., \& Monahan, C. J. (1987). What is person-environment congruence? Supplementary versus complementary models of fit. Journal of Vocational Behavior, 31(3), 268-277. doi:https://doi.org/10.1016/0001-8791(87)90043-1

Nuansoi, W., Suntiniyompukdee, A., \& Tahlah, A. (2017). Rice production in Rattaphum District, Songkhla Province, Thailand. International Journal of Business and Economic Affairs, 2(1), 18-30. doi:https://doi.org/10.24088/ijbea-2017-21004

Oudat, M. S., Ahmad, N., \& Yazis, M. (2016). The impact of macroeconomic variables and global events on banking system: Evidence from Jordanian banking system. Journal of Administrative and Business Studies, 2(1), 35-47. doi:https:// doi.org/10.20474/jabs-2.1.3

Peng, T., Y.C., G., \& Lin, J. (2006). Common method variances in research: Problem nature, impact, testing, and remediation. Journal of Management, 23(1), 77-98.

Phillips, J. D. (1990). The price tag on turnover. Personnel Journal, 69(12), 58-61.

Pimonratanakan, S., \& Pooripakdee, S. (2017). The human resource development in the learning organization for the organizational development. International Journal of Business and Economic Affairs, 2(3), 183-192. doi:https://doi.org/ 10.24088/ijbea-2017-23003

Podsakoff, P. M., MacKenzie, S. B., Lee, J.-Y., \& Podsakoff, N. P. (2003). Common method biases in behavioral research: A critical review of the literature and recommended remedies. Journal of Applied Psychology, 88(5), 879-883.

Pulakos, E. D., \& Wexley, K. N. (1983). The relationship among perceptual similarity, sex, and performance ratings in managersubordinate dyads. Academy of Management Journal, 26(1), 129-139. doi:https://doi.org/10.5465/256139

Rehman, S. (2017). Impact of career development on organizational commitment. International Journal of Business and Administrative Studies, 3(3), 100-111. doi:https://doi.org/10.20469/ijbas.3.10003-3

Rijal, S. (2016). The influence of transformational leadership and organizational culture on learning organization: A comparative analysis of the IT sector Thailand. Journal of Administrative and Business Studies, 2(3), 121-129. doi:https:// doi.org/10.20474/jabs-2.3.3

Rivenbark, L. (2004). Managing employee retention. HR Magazine, 49(3), 127-150.

Roczniewska, M., Retowski, S., \& Higgins, E. T. (2018). How person-organization fit impacts employees' perceptions of justice and well-being. Frontiers in psychology, 8, 2318. doi:https://doi.org/10.3389/fpsyg.2017.02318

Ruiz-Palomino, P., Martínez-Cañas, R., \& Fontrodona, J. (2013). Ethical culture and employee outcomes: The mediating role of person-organization fit. Journal of Business Ethics, 116(1), 173-188. doi:https://10.1007/s10551-012-1453-9

Saks, A. M., \& Ashforth, B. E. (1997). A longitudinal investigation of the relationships between job information sources, applicant perceptions of fit, and work outcomes. Personnel Psychology, 50(2), 395-426. doi:https://doi.org/10.1111/ j.1744-6570.1997.tb00913.x

Salvaggio, A. N. (2003). To help or to leave: Person-group fit as a correlate of aggregate organizational citizenship behavior and turnover (Unpublished doctoral dissertation). University of Maryland, College Park, Maryland, MY.

Schneider, B. (1987). The people make the place. Personnel Psychology, 40(3), 437-453. doi:https://doi.org/10.1111/ j.1744-6570.1987.tb00609.x

Taris, R., \& Feij, J. (2001). Longitudinal examination of the relationship between supplies-values fit and work outcomes. Applied Psychology, 50(1), 52-80. doi:https://doi.org/10.1111/1464-0597.00048

Tsai, H. (1999). The challenges facing Taiwan's high-tech industry and counter measures. Economic Situation and Review Journal, 5(1), 60-73.

Vancouver, J. B., \& Schmitt, N. W. (1991). An exploratory examination of person-organization fit: Organizational goal congruence. Personnel Psychology, 44(2), 333-352. doi:https://doi.org/10.1111/j.1744-6570.1991.tb00962.x

Weiss, H. M. (1978). Social learning of work values in organizations. Journal of Applied Psychology, 63(6), 711-718. doi: http://dx.doi.org/10.1037/0021-9010.63.6.711 
Weldon, E., \& Weingart, L. R. (1993). Group goals and group performance. British Journal of Social Psychology, 32(4), 307-334. doi:https://doi.org/10.1111/j.2044-8309.1993.tb01003.x

Wilk, S. L., \& Sackett, P. R. (1996). Longitudinal analysis of ability-job complexity fit and job change. Personnel Psychology, 49(4), 937-967. doi:https://doi.org/10.1111/j.1744-6570.1996.tb02455.x

Wu, T.-Y., \& Hu, C. (2009). Abusive supervision and employee emotional exhaustion: Dispositional antecedents and boundaries. Group \& Organization Management, 34(2), 143-169. doi:https://doi.org/10.1177/1059601108331217

Xie, Y. (2005). The effect of person and organization fit and person and job fit on work behavior (Unpublished master's thesis). Department of Business Administration, National Taiwan University of Science and Technology, Taipei, Tiawan.

Zheng, B. (1995). The up-and-down fit of organizational values and the effectiveness of individual members of the organization. Chinese Journal of Psychology, 37(1), 25-44. 